\title{
ANALYSIS AND SIMULATION OF A THREE-PHASE MULTILEVEL RECTIFIER
}

\section{*Zainab Adnan Kadhum}

1) University of Mustansiriyah, College of Engineering, Baghdad, Iraq

2) University of Mustansiriyah, College of Engineering, Baghdad, Iraq
Turki K. Hassan ${ }^{2}$

\begin{abstract}
This paper aims to design and simulate a fivelevel cascaded $\mathrm{H}$-bridge Pulse Width Modulation (PWM) rectifier with a three-phase supply. The voltage control loop and d-q currents control loops with the decoupled feed-forward control are suggested based on the vector control technique. Unity power factor at the supply with low harmonics input ac currents and control of dc output voltage of each $\mathrm{H}$-bridge with very little ripple is obtained. MATLAB / SIMULINK is used for simulation. The obtained results confirm the validity of the PWM rectifier model, and its control. Stability analysis of the PWM-Rectifier is also provided for selecting control parameters and evaluating the simulation.
\end{abstract}

Keywords: phase-shifted Pulse Width modulation, Cascaded H-bridge converter, synchronous reference frame.

\section{Introduction}

The key principle based on cascaded multi-level $\mathrm{H}$-bridge converters is to connect more cells of series H-bridge and clamp the voltages between their pins to achieve the voltage level with multiple steps [1]. The current literature [2][3] includes too many of the converter topologies present. The cascaded H-bridge (CHB) converter is suitable for both the ac-dc and dc-ac power conversion applications such traction systems, solid-state transformers, medium voltage drive, because of its simple structure, and reduced number of components [4]. A Cascaded H-Bridge PWM rectifier consists of multiple H-bridge cells. The ac terminals of these cells are connected in series and their dc sides are linked to different loads. Each Hbridge uses a high capacitance on the dc side to reduce the ripple of DC output voltages of $\mathrm{H}$ bridge cells and a line-side three-phase inductance to removed out the high frequencies other than line frequency, this produces a sinusoidal supply current. This paper suggested a control method for maintaining constant dc voltage across the load by comparing the average of the measured dc-load voltages with the required reference voltage using the PI controller [5][6].

A vector control strategy is suggested in [4][7] to produce reference voltages, which are sent to the phase-shifted carrier to get the switching pulses of the rectifier. This strategy also controls the output DC voltages of three-phase five-level cascaded $\mathrm{H}$-bridge active rectifier and 
compensates for the reactive power resulting in controllable power factor at the input terminals of AC supply and reduces the total harmonic distortion (THD) for the input AC supply currents. In this paper, a detailed study of the cascaded $\mathrm{H}$-bridge rectifier with vector control is provided and MATLAB / SIMULINK is used to verify the suggested active rectifier system.

\section{Modeling and Control of PWM Rectifier}

Figure 1 shows the circuit diagram for the active rectifier of a Cascaded H-bridge, three-phase, five-level. Every phase consisted of two cells of

$$
\theta_{s}=\frac{360}{n-1}
$$

used. This type of modulation provides normal switching frequency and equal power-sharing between the switching devices [4]. The number of series cells for its structure will be (n-1)/2 for n-level Cascaded H-bridge rectifier, as well as the number of triangular carrier waves for modulation, will be (n-1). As expressed in Eqn. (1), these triangular carrier waves are shifted with an angle of $\theta_{s}$.

$\mathrm{H}$-bridge connected in series at their ac sides to obtain low harmonic distortion and medium voltage operation. The dc-link voltage of each $\mathrm{H}$-bridge is connected to a distinct load [4].

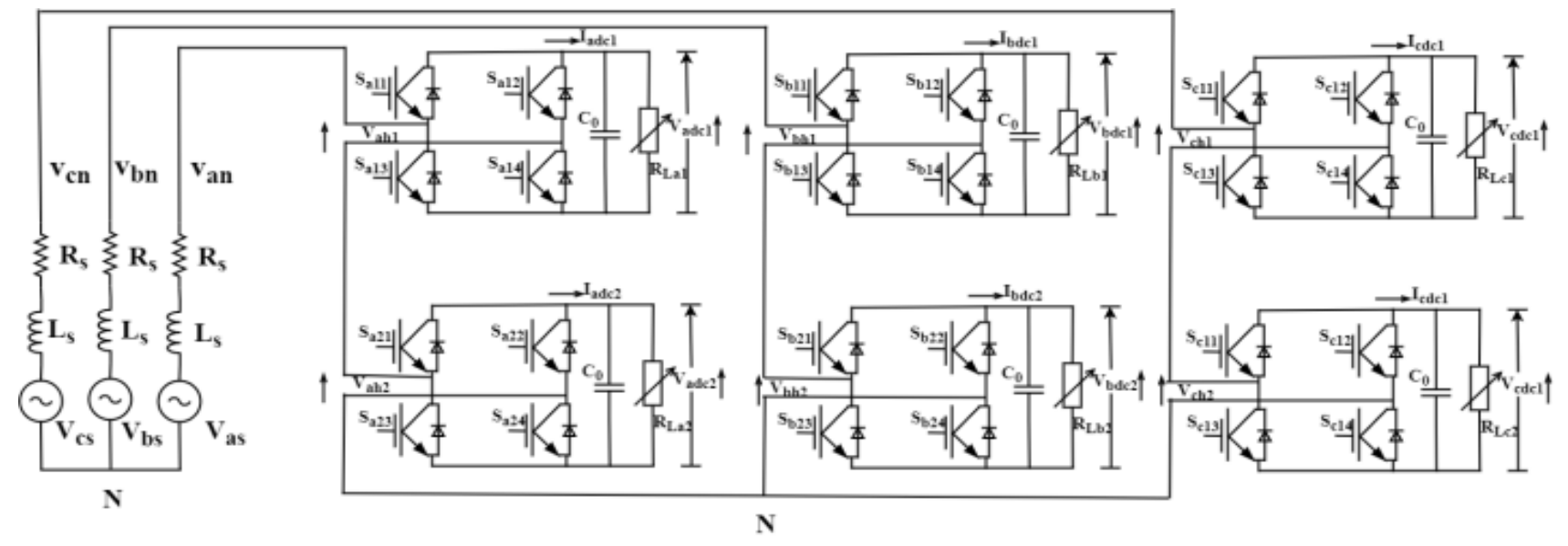

Figure 1.Three Phase 5-level Cascaded H-Bridge rectifier

The impedance on the ac-side is modeled in series as an inductor $L_{s}$ with small value resistor $R_{s}$. The dc voltage and current are $V_{d c}$ and $I_{d c}$ respectively. The capacitor on dc-side is $C_{0}$. The upper and lower power switch control signals in the same voltage-source converter bridge arm are complementarily turned on to prevent the short circuit on the dc side. It is possible to control the dc-link capacitor voltages by using different control and modulation methods. A phase-shifted PWM modulation is

(1)




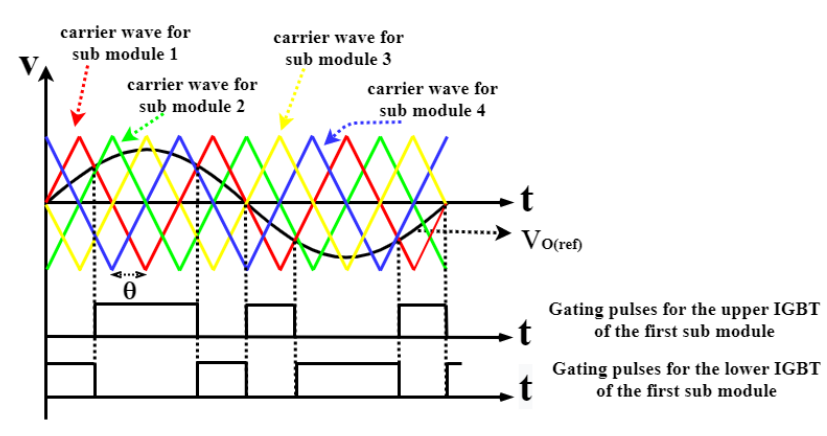

Figure 2. phase-shifted PWM Technique

Equations that describe the boost type rectifier's dynamic behavior in the $\mathrm{d}-\mathrm{q}$ coordinates can be expressed as [7]:

$$
\begin{gathered}
L \frac{d i_{d}}{d t}=v_{d}-i_{d} R_{s}+\omega L_{s} i_{q}-E_{d} \\
L \frac{d i_{q}}{d t}=v_{q}-i_{q} R_{s}-\omega L_{s} i_{d}-E_{q} \\
\operatorname{Co} \frac{d V_{d c}}{d t}=-\frac{V_{d c}}{R_{L}}+\frac{3}{2}\left(S_{d} i_{d}+S_{q} i_{q}\right)
\end{gathered}
$$

Where $E_{d}, E_{q}$, and $S_{d}, S_{q}$ are rectifier input voltage, switch function in the d-q coordinate of synchronous rotation, respectively. $v_{d}, v_{q}$ and $i_{d}, i_{q}$ is the source of the voltage, the current in the synchronous $\mathrm{d}-\mathrm{q}$ coordinate, respectively. The angular frequency is the $\omega_{c}$.

\section{Control system analysis}

Vector control, which is generally an effective method used to control induction motor drives is applied for control of a three-phase cascaded $\mathrm{H}$ bridge rectifier. The theory of the aim is to use a decoupled method to control the components required to generate the torque and the flux. A similar analysis will also be applied to a threephase active rectifier. The three-phase stationary system is transformed into $\mathrm{d}-\mathrm{q}$ decoupled synchronously rotating reference frame components that are used to control the active and reactive powers. The $\mathrm{d}-\mathrm{q}$ current rectifier control loops and DC voltage loop are shown in Figure 3.

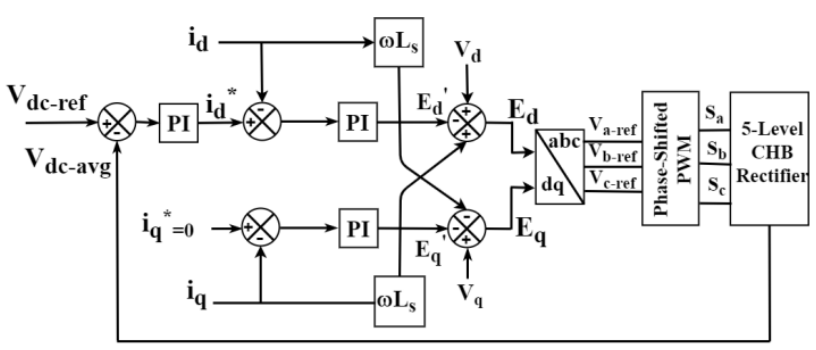

Figure 3. Block Diagram of overall Control system

The $\mathrm{d}-\mathrm{q}$ voltage commands can be expressed as:

$E_{d}=-E_{d}^{\prime}+\omega L_{s} i_{q}+v_{d}$
$E_{q}=-E_{q}^{\prime}-\omega L_{s} i_{d}+v_{q}$

In the current regulation, the proportionalintegral controllers of the PI regulator $\left(K_{i P}, K_{i I}\right)$ are applied, $\left(E_{d}\right.$ and $\left.E_{q}\right)$ is controlled by the following expression:

$$
\begin{gathered}
E_{d}=-\left(K_{i P}+\frac{K_{i I}}{S}\right)\left(i_{d}{ }^{*}-i_{d}\right)+\omega L_{s} i_{q} \\
+v_{d} \\
E_{q}=-\left(K_{i P}+\frac{K_{i I}}{S}\right)\left(i_{q}^{*}-i_{q}\right)-\omega L_{s} i_{d} \\
+v_{q}
\end{gathered}
$$

From Fig.4, power equations can be expressed in d q-frame as:

$$
\begin{aligned}
P_{\text {in }} & =\frac{3}{2}\left[v_{d} i_{d}+v_{q} i_{q}\right] \\
Q_{\text {in }} & =\frac{3}{2}\left[-v_{d} i_{q}+v_{q} i_{d}\right]
\end{aligned}
$$




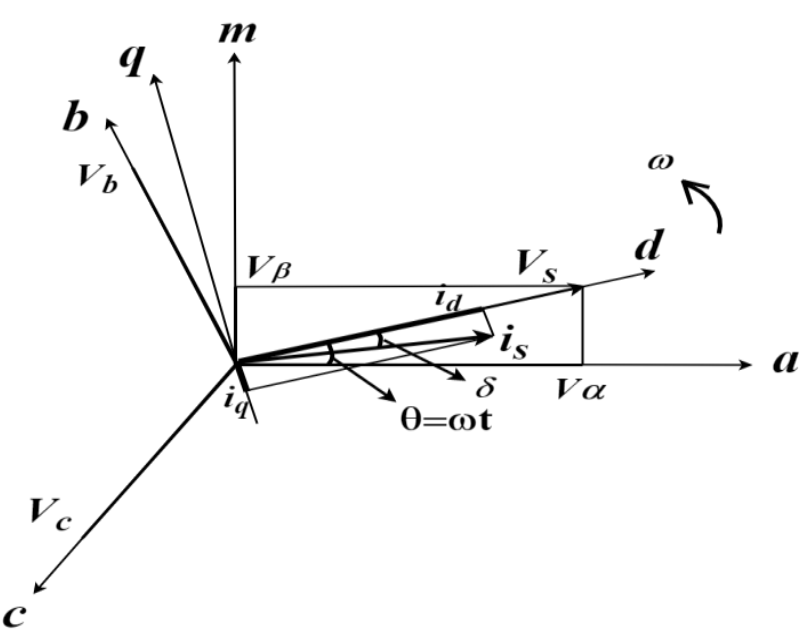

Figure 4. d-q Reference Frame

The $\mathrm{d}$-q reference frame is built to always align the d-component of the voltage vector with the possible results of the stationary frame $\left(\overleftarrow{V_{S}}\right)$ ABC voltages as shown in Figure. 4. And the voltage of the q-axis will be zero $\left(V_{q}=0\right)$, and the Eqn. (9) (10) maybe replicated as:

$P_{\text {in }}=\frac{3}{2} v_{d} i_{d}$

$Q_{\text {in }}=0$

The equations of (2-4) and (11-12) are used to design and control of the cascaded H-Bridge rectifier as shown in Fig. 3. The voltage $v_{d}$ is constant when the three-phase supply voltages are fixed. The difference between the reference value of dc voltages $\left(V_{d c-r e f}\right)$ and the average value of all dc-link voltages $\left(V_{d c-a v g}\right)$ of active rectifier are applied to the PI controller to produce the real power reference current $I_{d_{-}}$ref . The q-current component controller aims to keep the rectifier's reactive power consumed at zero $\left(Q_{i n}=0\right)$ to obtain the condition of unity power factor at the input terminals. This condition can be obtained when the reactive power component $i_{q}$ has a reference value of zero (Eqn. (10)).

\section{Stability Analysis}

As has been mentioned, including in Fig (3), there is a cross-coupling between the quantities of the d-axis and the q-axis. And, as described in Fig (5). There are voltage and current control loops in the vector controlled converter [8].

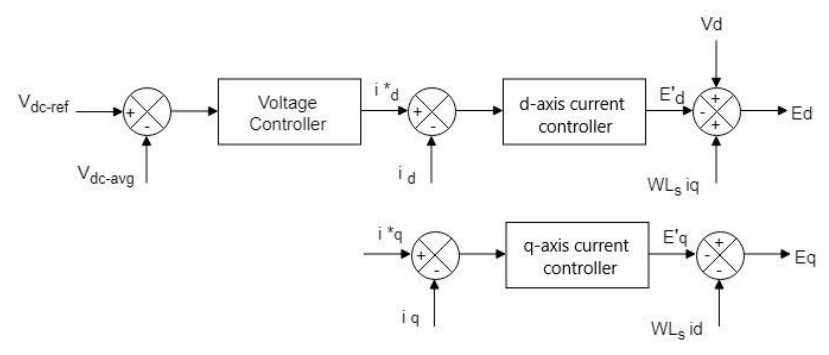

Figure 5. Voltage and current control loops system

The current d-component loop is shown in figure 6. $\mathrm{G}$ is the gain, as shown in Eqn. (13), from $V_{d c-r e f}$ to $V_{t r i}$. $\left(V_{t r i}\right.$ is the triangular carrier peak used in phase-shifted PWM) [8]

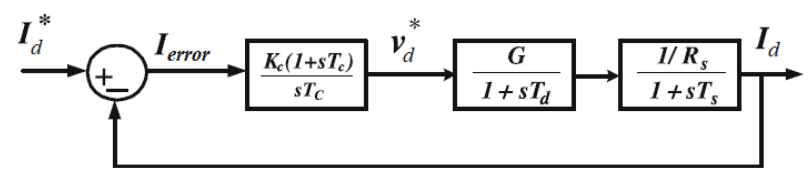

Figure 6. d-component current control loop

$G=\frac{V_{d c-r e f}}{2 V_{t r i}}$

$T_{d}$ is the time of delay and equals half the duration of the carrier signal, $T_{S}$ is the inductance time constant $\left(T_{s}=L_{s} / R_{s}\right)$. The open-loop transfer function between $I_{d}$ and $I_{\text {error }}$ will then be selected by the controller parameter $T_{c}$ equals $T_{S}$ (for pole-zero cancellation) [8].

$\frac{I_{d}(s)}{I_{\text {error }}(s)}=\frac{K_{c} G}{s T_{s} R_{s}\left(1+s T_{d}\right)}$ 
and the closed-loop transfer function will be as

$\frac{I_{d}(s)}{I_{d}^{*}(s)}=\frac{K_{c} G}{T_{s} T_{d} R_{s}} \frac{1}{\left(s^{2}+\frac{1}{T_{d}} s+\frac{K_{c} G}{T_{s} T_{d} R_{s}}\right)}$

By comparing the R.H.S denominator of Eqn. (15) with a second-order transfer function in the standard form

$2 \xi \omega_{n}=\frac{1}{T_{d}} \quad \& \omega_{n}^{2}=\frac{K_{c} G}{T_{s} T_{d} R_{s}}$

Choosing $\xi=0.707$ [8], the gain of the current controller is determined as

$K_{c}=\frac{T_{s} R_{s}}{2 T_{d} G}$

By substituting $K_{c}$ in Eqn. (15) will yield the following approximation:

$$
\frac{I_{d}(s)}{I_{d}^{*}(s)}=\frac{1}{\left(2 T_{d}^{2} s^{2}+2 s T_{d}+1\right)}
$$

The voltage loop desired bandwidth is much smaller than the current loop bandwidth; therefore, the second-order term in the denominator polynomial in (17) may be ignored. Thus a transfer function for the first order is expressed in Eqn. (18) can refer to the current loop.

$\frac{I_{d}(s)}{I_{d}^{*}(s)} \cong \frac{1}{\left(1+2 s T_{d}\right)}$

Next, Figure 7 shows the block diagram of the voltage loop. Where $K_{1}$ and $T_{1}$ are respectively the gain and time constant of the DC voltage filter output and $K_{v}, T_{v}$ are the parameters of the voltage controller. The voltage loop openloop transfer function is assigned out in equation (19).

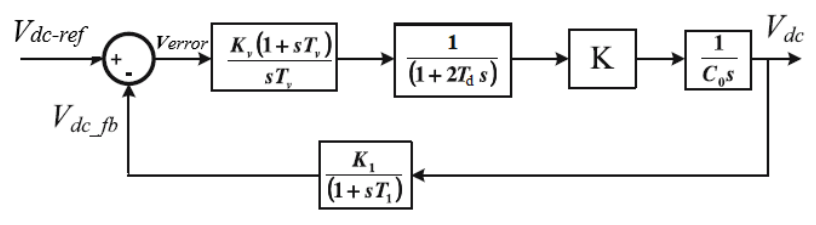

Figure 7. Voltage control loop

$\frac{V_{d c_{-} f b}(s)}{V_{\text {error }}(s)}$
$=\frac{K_{e}\left(1+s T_{v}\right)}{s T_{v}\left(1+2 T_{d} s\right)\left(1+s T_{1}\right) C_{0} s}$

Where

$K_{e}=K_{v} K K_{1} \& K=\frac{v_{d}}{4 v_{d c}}$

$\frac{V_{d c_{-} f b}(s)}{V_{\text {error }}(s)}$

$=\frac{K_{e}\left(1+s T_{v}\right)}{s^{2} T_{v} C_{0}\left(1+2 T_{d} s+s T_{1}+2 T_{d} T_{1} S^{2}\right)}$

$\frac{V_{d c-f b}(s)}{V_{\text {error }}(s)} \cong \frac{K_{e}\left(1+s T_{v}\right)}{s^{2} T_{v} C_{0}\left(1+s 2 T_{d}\right)}$

The open-loop transfer function in Eqn. (22) contains two poles at the origin so that the magnitude plot has a low-frequency slope of $-40 \mathrm{~dB} /$ decade as shown in Fig. 8. For system stability [8], the zero controller $\left(\omega_{1}=1 / T_{v}\right)$ should be positioned before $\omega_{c}\left(\omega_{c}\right.$ is the unit gain crossover) and pole $\left(\omega_{2}=1 / 2 T_{d}\right)$ should be positioned after unit gain crossover so that the crossover slope is $-20 \mathrm{~dB} /$ decade as shown in figure (8). 


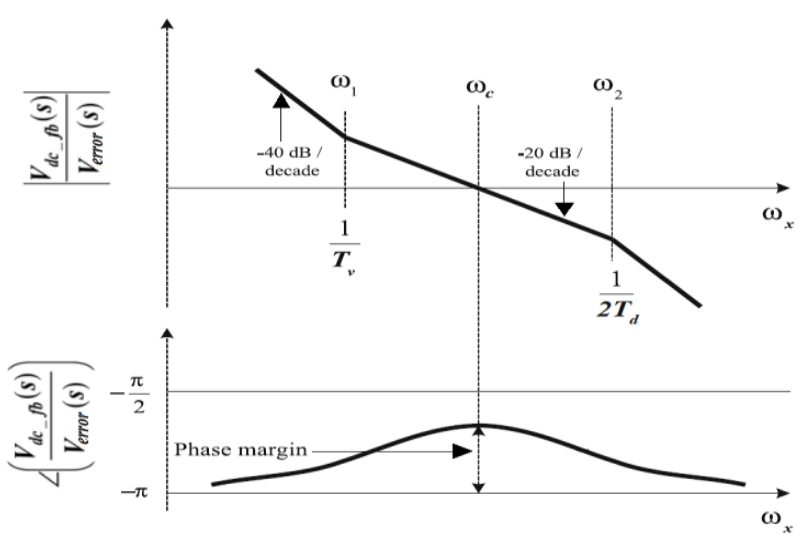

Figure 8. Bode Plot of the voltage control loop

Then $\omega_{c}$ which is the geometric mean of the two corner frequencies $\left(1 / T_{v}\right)$ and $\left(1 / 2 T_{d}\right)$ can be expressed as in (23)

$\omega_{c}=\frac{1}{\sqrt{T_{v}\left(2 T_{d}\right)}}=\frac{1}{a\left(2 T_{d}\right)}$

Thus,

$T_{v}=2 a^{2} T_{d}$

; $\mathrm{a}$ is any number greater than $1[8]$

By making the crossover frequency gain is equal to one and as explained in (25), the parameter $K_{v}$ can be expressed as an equation in (26).

$\left|\frac{V_{d c_{-} f b}(s)}{V_{\text {error }}(s)}\right|_{\omega_{x}=\omega_{c}}=1$

$=\frac{K_{e} \sqrt{1+\left(\omega_{c} T_{v}\right)^{2}}}{\omega_{c}^{2} C_{0} T_{v} \sqrt{1+\left(\omega_{c}\left(2 T_{d}\right)\right)^{2}}}$

$K_{v}=\frac{T_{v} C_{0}}{K_{1} K}$

Table 1 shows the parameters of the active rectifier system.
Table 1: Control system parameters

\begin{tabular}{|c|c|c|c|}
\hline Parameter & Value & Parameter & Value \\
\hline $\mathrm{V}_{\mathrm{s}(\mathrm{ph}-\mathrm{ph}, \mathrm{rms})}(\mathrm{V})$ & 220 & K & 0.07484 \\
\hline $\mathrm{V}_{\mathrm{dc} \_ \text {ref }}(\mathrm{V})$ & 600 & $\mathrm{~K}_{1}$ & 0.0011 \\
\hline $\mathrm{R}_{\mathrm{s}}(\Omega)$ & 0.02 & $\mathrm{~T}_{1}(\mu \mathrm{S})$ & 10 \\
\hline $\mathrm{L}_{\mathrm{s}}(\mathrm{H})$ & 0.006 & $\mathrm{~K}_{\mathrm{c}}$ & 8 \\
\hline $\mathrm{C}_{0}(\mu \mathrm{F})$ & 1000 & $\mathrm{~T}_{\mathrm{s}}=\mathrm{T}_{\mathrm{c}}(\mathrm{mS})$ & 300 \\
\hline $\mathrm{R}_{\mathrm{L}}(\Omega)$ & 200 & $K_{v}$ & 0.02429 \\
\hline $\mathrm{f}_{\mathrm{SW}}(\mathrm{Hz})$ & 2000 & $\mathrm{~T}_{\mathrm{v}}(\mathrm{mS})$ & 2 \\
\hline G & 1.5 & $\mathrm{a}$ & 2 \\
\hline
\end{tabular}

The rectifier should be more stable and have a greater margin of stability when using a higher dc-side capacitor $C_{0}$, or lower filter inducer $L_{s}$, even with load change or disturbance on supply. Additionally, if the $L_{s}$ value is too small, the distortion of the input current will increase. Similarly, a higher value of $C_{0}$ will increase the volume of the system, and a slower dynamic response to the voltage loop. So when selecting $L_{s}$ and $C_{0}$ parameters, a trade-off must be made between system stability and other performance.

\section{Simulation Results}

MATLAB / SIMULINK is used for simulation of a $10.8-\mathrm{kW}$ ac / dc converter simulation model for the three-phase five-level cascaded H-Bridge Active Rectifier with vector control. The simulation model parameters in Table 1 are applied for studying the converter's behavior under different operating conditions. The model for the simulation is shown in Fig.9. 


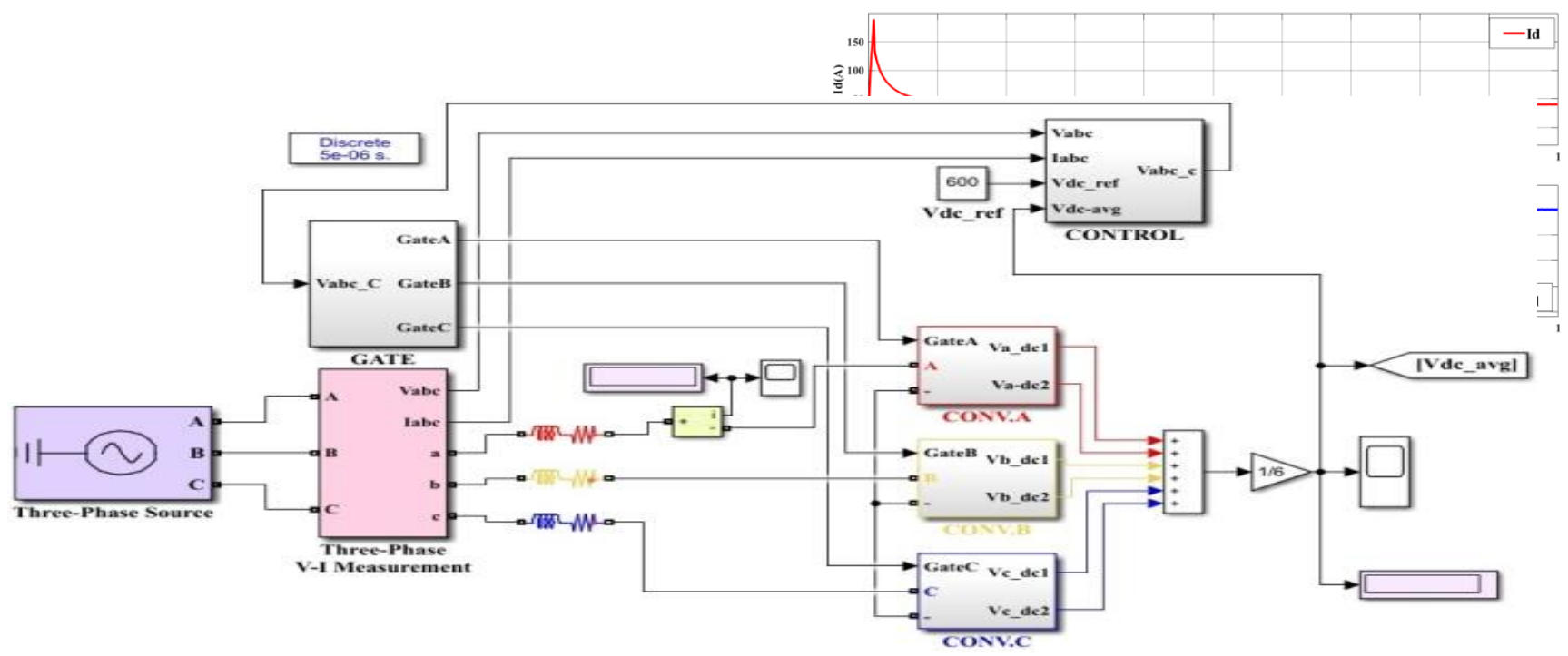

Figure 9. MATLAB model of a complete system

Figure 10, shows the three-phase reference voltage with THD nearly $20 \%$, which will be compared with phase-shifted triangular carrier signals to obtain PWM switching control pulses for transistors of the rectifier.

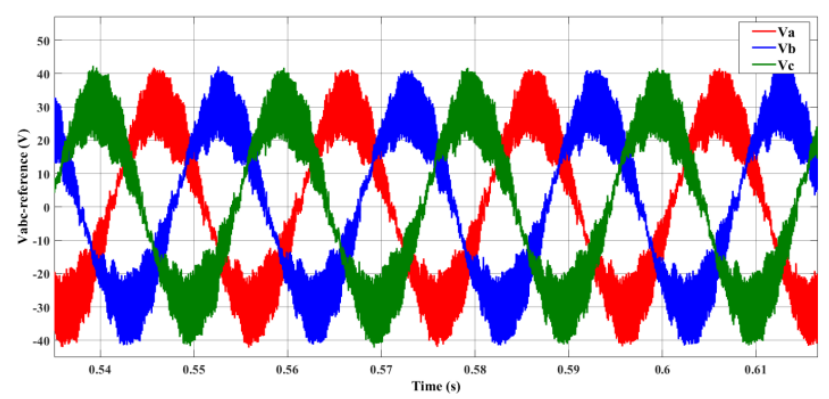

Figure 10. Three-phase reference voltage

The d q-component currents of the supply are shown in Figure (11) where $i_{d}$ is equal to $40 \mathrm{~A}$ with ripple about $0.8 \mathrm{~A}$ (p.p), whereas $i_{q}$ has a zero value to consume the reactive power tends to result in a unity power factor.
Figure (12) describes the dq- voltage component transformed from a voltage source, $v_{d}$ with a value of $180 \mathrm{~V}$ and with very small ripple and $v_{q}$ is like $i_{q}$ has a zero value.

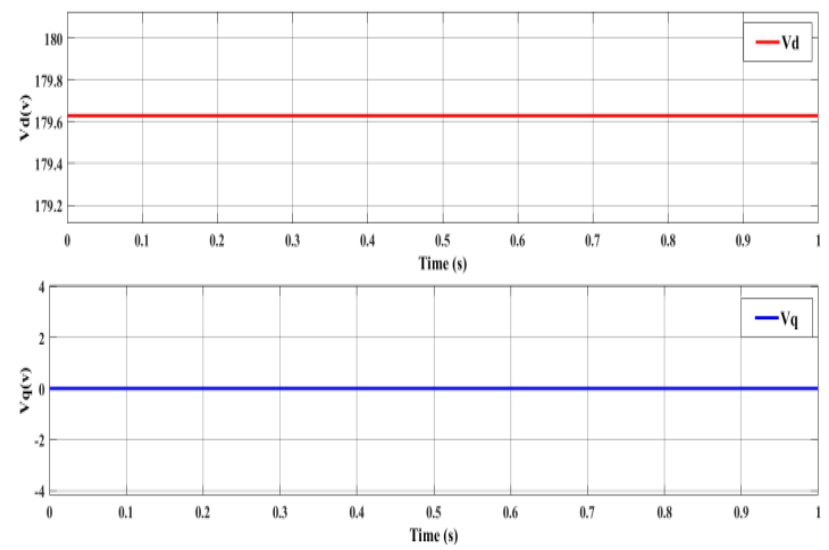

Figure 12. $v_{d} \& v_{q}$ response 
The average output dc voltage of the rectifier $V_{d c-a v g}$ is shown in figure (13) and compared with the reference voltage $V_{d c-r e f}$ at $600 \mathrm{~V}$.

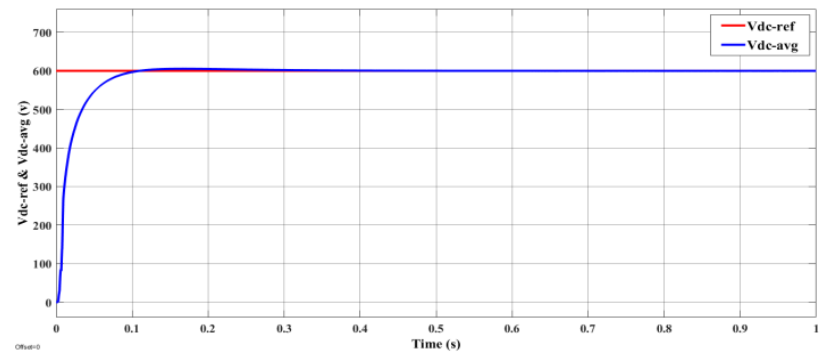

Figure 13. The DC output voltage (reference and average)

The DC output current of one bridge is shown in figure (14) with a ripple of $0.1 \mathrm{~A}$ (p.p) and its average value of $3 \mathrm{~A}$ when a resistive load of $200 \Omega$ is connected across the output of each $\mathrm{H}$ bridge of the rectifier.

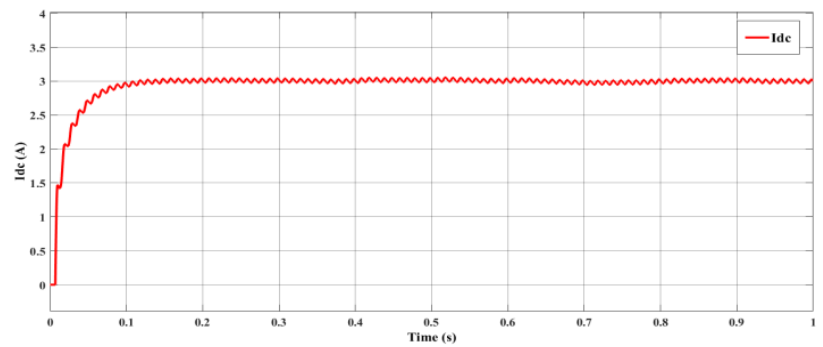

Figure 14. DC output current $I_{d c}$ for a single bridge

The phase A voltage and current are shown in figure (15) with low THD for supply current (approximately $0.62 \%$ ) and the rectifier operates with a unity power factor.

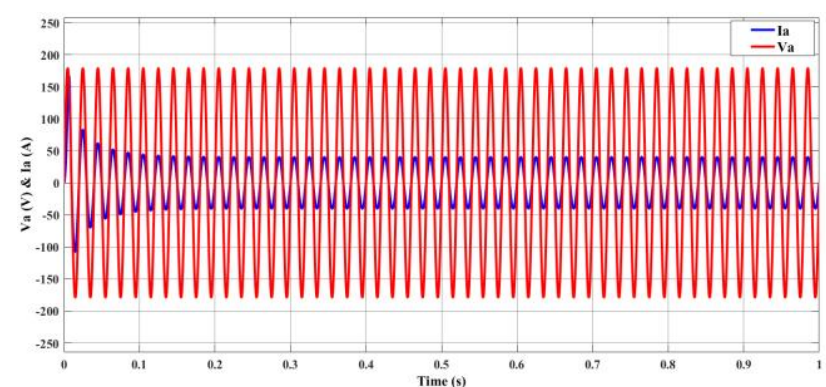

Figure 15. Voltage and Current of phase A

To test the converter's behavior under variable load conditions, the loads are adjusted from $R_{L}$ $=200 \Omega$ to $20 \Omega$ at $\mathrm{t}=0.3 \mathrm{~s}$ and then increased to $200 \Omega$ at $\mathrm{t}=0.65 \mathrm{~s}$. The dc controlled voltage will directly change as the load changes then it will return to stabilize with the reference voltage with a time of 0.35 from the instant of the load change and shoot off $5 \%$ as shown in figure 16

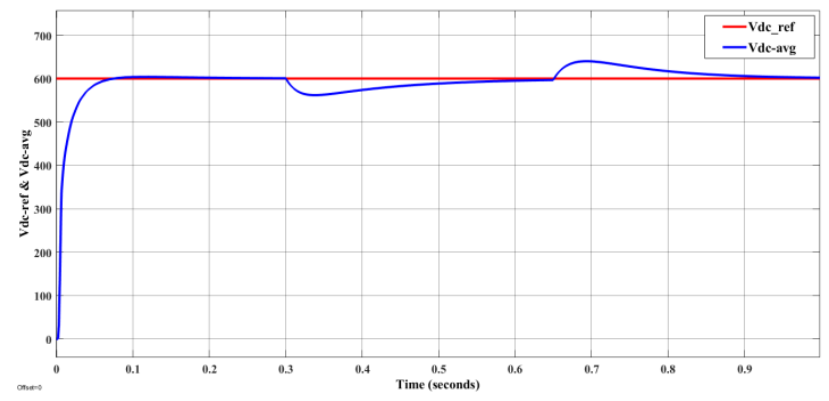

Figure 16. The DC output voltage with the change of load

Figure 17 shows input currents for the d- and qcomponents. For the time $t=0.3 \mathrm{~s}$, the magnitude of d-component of the current is increased as the load is reduced to $20 \Omega$ then decreased when the load increased to $200 \Omega$.To achieve the unity power factor, the q- component current $\left(i_{q}\right)$ is always maintained at zero value. 


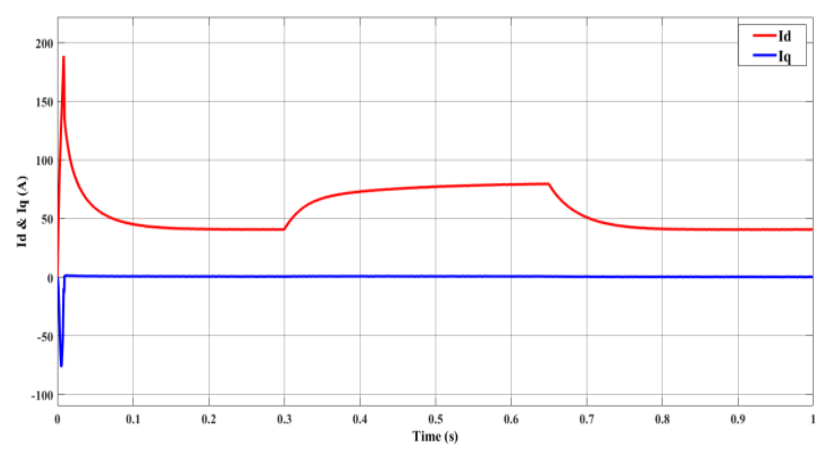

Figure 17. d-q currents

The current $\mathrm{d}$-component change reflects the current input, as shown in Fig. 18, where the magnitude of the ac current (phase A) is increased during a low load then it decreases when the load increased. THD will change slightly when the load changes.

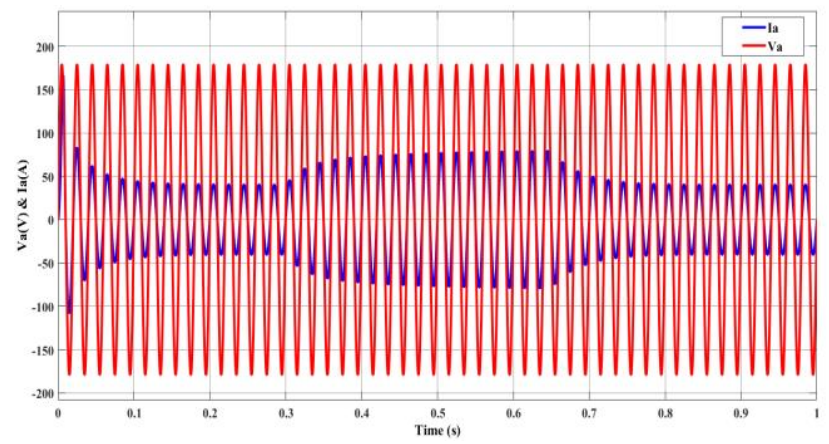

Figure 18. Voltage \& Current (phase A)

To show the dynamic behavior of the control system against the variation of supply voltage, figure 19 shows the dc output voltage response when the three-phase supply voltages are increased to $375.58 \mathrm{~V}$ (amplitude of phase voltage) at time of $0.4 \mathrm{~s}$ and decreased to its original value of $179.62 \mathrm{~V}$ at time of $0.7 \mathrm{~s}$ with a shoot of $5 \%$ and the voltage returns to its original value at steady state.

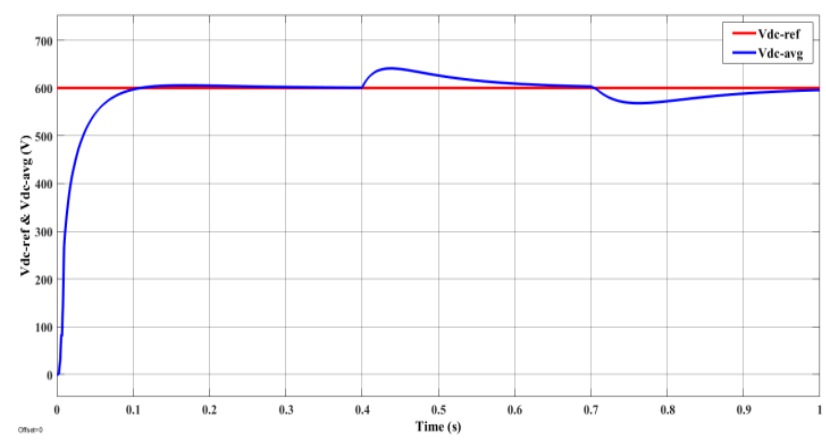

Figure 19. The DC output voltage

Figure 20 shows the $\mathrm{d}-\mathrm{q}$ currents response for a variety of supply voltage. The $i_{d}$ is reduced when supply voltage increases to maintain constant output power and $i_{q}$ remains at zero value for zero reactive power.

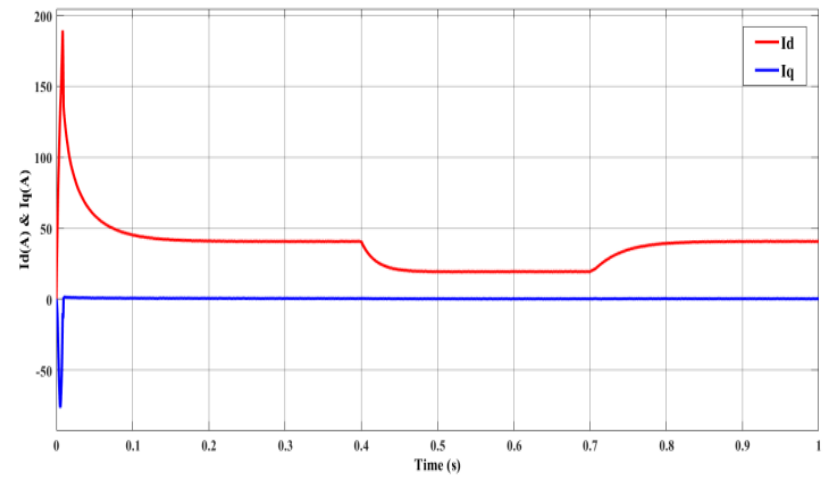

Figure 20. d-q currents

Figure 21 shows the phase A supply voltage and current. The supply current is reduced when the supply voltage increases to maintain constant output power with unity power factor. 


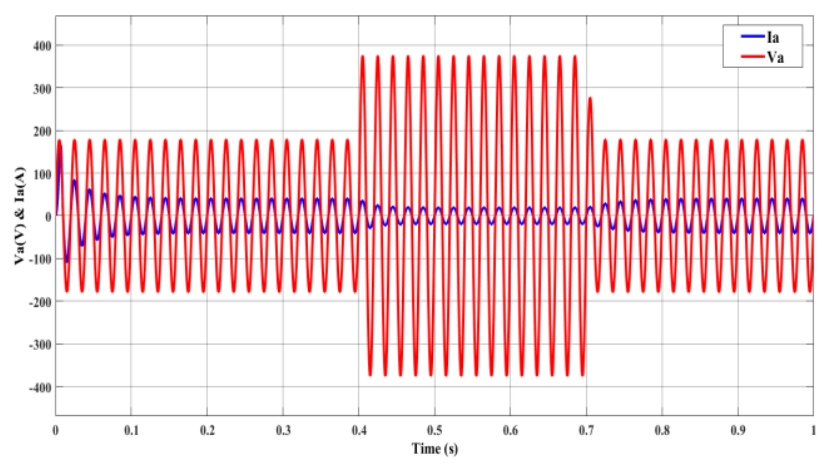

Figure 21. Voltage \& Current supply (phase A)

\section{Conclusion}

A full analysis of three-phase five-level active rectifier is presented in this paper. To obtain a constant DC output voltage for each $\mathrm{H}$-bridge cell of active rectifier and unity power factor, the vector control technique is suggested. Based on simulation results, the DC output voltages of rectifier cells are regulated to match the reference voltage at a steady-state irrespective of variations of applied loads or AC supply voltage. The q-component of current is set to zero to obtain zero reactive power, therefore the AC input current is always in phase with supply voltage.

\section{Conflict of interest}

The authors declare that there is no conflict of interest regarding the publication of this paper.

\section{Reference}

1. Chowdhury, MD Shajjad (2017). "A multilevel converter with a floating bridge for open-ended winding motor drive application". Ph.D. Thesis, University of Nottingham.

2. J. Rodriguez, Jih-Sheng Lai, and Fang Zheng Peng (2002). Multilevel inverters: $a$ survey of topologies, controls, and applications. IEEE Transactions on Industrial Electronics, vol. 49, no. 4, pp. 724-738.
3. J. Rodriguez, S. Bernet, Bin Wu, J. O. Pontt, and S. Kouro (2007). Multilevel VoltageSource-Converter Topologies for Industrial Medium-Voltage Drives. IEEE Transactions on Industrial Electronics, vol. 54, no. 6, pp. 2930-2945.

4. J. Venkat and A. Shukla (2014). "Operation of a three-phase cascaded H-bridge multilevel active rectifier under variable DC loads". IEEE Int. Conf. on Power Electronics, Drives and Energy Systems.

5. C. Cecati, A. Dell'Aquila, M. Liserre, V. G. Monopoli (2003). Design of H-bridge multilevel active rectifier for traction systems. IEEE Transactions on Industry Applications, vol. 39, no. 5, pp. 1541-1550.

6. H. Iman-Eini, J. L. Schanen, S. Farhangi, and J. Roudet (2008). A Modular Strategy for Control and Voltage Balancing of Cascaded H-Bridge Rectifiers. IEEE Transactions on Power Electronics, vol. 23, no. 5, pp. 2428-2442.

7. X. Wang, K. Huang, S. Yan, and B. Xu (2008). "Simulation of three-phase voltage source PWM rectifier based on direct current control" 1st Int. Cong. on Image and Signal Processing.

8. J S Siva Prasad, Tushar Bhavsar, Rajesh Ghosh, and G Narayanan (2008). Vector control of three-phase AC/DC front-end converter. $S^{-}$adhan ${ }^{-}$, Vol. 33, Part 5, pp. 591-613.

9. S. He, J. Xiong, and D. Dai (2018). "Modeling and Stability Analysis of ThreePhase PWM Rectifier" IEEE International Power Electronics and Application Conference and Exposition.

10. S. Hiti and D. Boroyevich (1994). "Control of front-end three-phase boost rectifier" in Conference Proceedings - IEEE Applied Power Electronics Conference and Exposition.

11. N. Jayaram, P. Agarwal, and S. Das (2012). "A three-phase five-level cascaded $\mathrm{H}$-Bridge rectifier with sinusoidal PWM scheme" IEEE 5th Power India Conference.

12. T. Zhao, G. Wang, S. Bhattacharya, and A. Q. Huang (2013). "Voltage and power balance control for a cascaded h-bridge 
converter-based solid-state Transformer" IEEE Trans. Power Electron.

13. Chowdhury, MD Shajjad (2017). "A multilevel converter with a floating bridge for open-ended winding motor drive application". Ph.D. Thesis, University of Nottingham.

14. T. Shimizu (1997). "A unity power factor $P W M$ rectifier with dc ripple compensation" IEEE Trans. Ind. Electron. 